\title{
The buzz before business: a design science study of a sustainable entrepreneurial ecosystem
}

\author{
Gregory O'Shea • Steffen Farny • Henri Hakala
}

\begin{abstract}
This paper examines how entrepreneurial opportunities co-evolve within a sustainable entrepreneurship ecosystem (SEE). Most of the literature on entrepreneurial ecosystems falls short on integrating the entrepreneurial process in empirical research. To analyze data collected from pre-start-up teams within a nascent SEE on high-tech cellulose-based materials over 3 years, we apply a design science approach that helps understand actors' collaborative sensemaking in designing and structuring ecosystem features and relationships. Our findings show that the SEE can be seen as a design artifact which evolves by ecosystem actors collectively engaging in new venture ideation and developing opportunity confidence. Furthermore, the paper presents a novel SEE framework, which elaborates on phases and enablers of the opportunity co-evolution process within an emerging ecosystem. We contribute to the literature
\end{abstract}

Electronic supplementary material The online version of this article (https://doi.org/10.1007/s11187-019-00256-4) contains supplementary material, which is available to authorized users.

G. O'Shea $(\bowtie) \cdot$ H. Hakala

School of Business and Management, LUT University, Lappeenranta, Finland

e-mail: gregory.oshea@lut.fi

\section{H. Hakala}

e-mail: henri.hakala@lut.fi

S. Farny

School of Business, Aalto University, Espoo, Finland e-mail: steffen.farny@aalto.fi on sustainable as well as general entrepreneurial ecosystems and offer a new theoretical foundation for a process view on ecosystems.

Keywords Design science study · Entrepreneurial ecosystem $\cdot$ Buzz $\cdot$ Opportunity process $\cdot$ Sustainable entrepreneurship

JEL classification $\mathrm{L} 26 \cdot \mathrm{L} 73 \cdot \mathrm{M} 13 \cdot \mathrm{O} 31 \cdot \mathrm{O} 35$

\section{Introduction}

Sustainable entrepreneurial ecosystems driving the economy are a major future trend. A sustainable entrepreneurial ecosystem (SEE) can be defined as "an interconnected group of actors in a local geographic community committed to sustainable development through the support and facilitation of new sustainable ventures" (Cohen 2006, p. 3). Researchers largely agree that it is necessary to transition towards sustainable business practices in order to address pressing socio-ecological needs, i.e., the resource depletion, pollution, and biodiversity loss that endanger the Earth's carrying capacity and thereby jeopardize the socioeconomic stability of societies around the globe (Rockström et al. 2009). As a call for action, in its Sustainable Development Goals, the UN has requested developing joint efforts by the private, public, and nonprofit sectors to achieve the necessary sustainability impact. In response to this grand challenge, entrepreneurial ecosystems research provides a distinctive multi-actor point of entry through which to study the geography of 
high-growth entrepreneurship and suggest active economic policies (Spigel 2017) with a generative potential for the global sustainability agenda. Despite the emphasis on this as an important research area, at present, such sustainable entrepreneurial ecosystem research is largely missing (Bischoff and Volkmann 2018).

As a starting point, the SEE concept can broadly be seen as a regional development strategy with the objective of nurturing sustainable new ventures that create social, environmental, and economic value in a community (Cohen 2006; Spigel and Harrison 2018). So far, broader entrepreneurial ecosystems research has highlighted the importance of a community of actors which support the development of new high-growth ventures (Spigel and Harrison 2018; Theodoraki et al. 2018), as well as structural attributes of successful entrepreneurial ecosystems (Audretsch and Belitski 2017; Autio et al. 2018; Spigel 2017). However, as some point out (Autio et al. 2018; Spigel 2017), many of the studies on entrepreneurial ecosystems are rather typological and atheoretical in nature and currently neglect integrating the entrepreneurial process in further developing the concept (for a notable exception, see Spigel and Harrison 2018): "It is important to understand how resources flow within the ecosystem, how they are produced by internal mechanisms such as recycling of both successful and unsuccessful ventures, and how they can also be attracted into the ecosystem by the global pipelines entrepreneurs create" (Spigel and Harrison 2018, p. 165).

In the interest of developing the SEE concept, we suggest more strongly integrating the process understanding of the literature on entrepreneurship (Davidsson 2015; Dimov 2018; McMullen and Dimov 2013) and sustainable entrepreneurship (Belz and Binder 2017; Farny et al. 2018; Muñoz and Cohen 2018). For instance, the emergent process view of entrepreneurship emphasizes how ideas are converted into tangible ventures (Dimov 2007; Lichtenstein and Kurjanowicz 2010), predominantly featuring the discovery or creation of entrepreneurial opportunities (Venkataraman 1997). For sustainable entrepreneurship, this opportunity discovery or creation process is likely triggered by recognizing an a priori social or ecological problem (Belz and Binder 2017; Muñoz and Cohen 2018). In this paper, however, we adopt what Davidsson (2015) has termed an evolving idiosyncratic view of opportunities, rather than the traditional discovery or creation view. In essence, the assumption here is that an opportunity unfolds from a seed venture idea and that this opportunity can change considerably over the course of its development (Dimov 2011; Sarason et al. 2006; Wood and McKinley 2010). We argue that the multi-actor, evolving idiosyncratic view of opportunities is most suitable to develop a process view of entrepreneurial ecosystems (Spigel and Harrison 2018) in which generative technological innovations unleash an ex-ante unknown number of potential opportunities for various actors in a SEE community (Dattée et al. 2018). In this vein, opportunity evolution occurs at a community or regional level, hence motivating our research question: how do entrepreneurial opportunities coevolve within a sustainable entrepreneurial ecosystem?

Our insights are based on a 3-year engaged scholarship approach on a generative technology, i.e., a technology that has the potential to create unprompted change and an astounding number of applications (Dattée et al. 2018). We sampled a regional entrepreneurial effort that has attempted to create high-tech sustainability innovations to qualify as a SEE, which we encountered in the environment of nanocellulosic material innovation in metropolitan Helsinki, Finland. The purpose of the Sustainable Cellulose Ecosystem Project (SCEP) is to create entirely new product portfolios to replace environmentally less sustainable materials such as cotton and plastic. It extends the cellulosic ecosystem through design and novel technologies to include viable alternatives to fossil-based synthetic materials and provides real alternatives for using raw materials in commodity products. In short, the SCEP introduces a sustainability turn to a well-established entrepreneurial ecosystem, ultimately in order to develop new sustainable product concepts and product-service systems. For our research purpose, entering the nanocellulose project provided us with a unique possibility for an early-stage engagement within a de novo technology-driven SEE, instead of the typical retrospective studies of established entrepreneurial ecosystems (e.g., Audretsch and Belitski 2017; Theodoraki et al. 2018).

Based on our inductive, design-driven analysis (Dimov 2018) of data collected in over 70 research meetings, interviews, and via archival records, we challenge the assumption in ecosystems literature that entrepreneurial opportunities and value propositions can be known ex-ante (cf. Dattée et al. 2018). Taking a design science perspective, we conceptualize the SEE as an artifact (Selden and Fletcher 2015) shaped by the members constituting the ecosystem. Similar to the Business 
Model Canvas - a design artifact - that helps structure the decision space on business model ontology (Dimov 2016), the SEE helps the community to structure and assign relative importance to different features and interrelations of their sustainable entrepreneurial endeavor. In our analysis, we derive a novel framework of collaboratively designing-cointuiting, co-interpreting, and co-integrating - a nascent ecosystem.

Building on our findings, we generate several contributions to the entrepreneurial ecosystem literature. First, our study adds to the emerging literature on sustainable entrepreneurial ecosystems (Cohen 2006) by clarifying the "buzz" in a community that has come together in an attempt to build a new sustainable ecosystem. A shared wish for sustainability and a supportive emotional climate enables the collective creation not only of new knowledge but also of socio-ecologically impactful business, and hence, such communities are metaenablers for a sustained engagement with the ecosystem beyond an individual's efforts at venture creation. Second, we advance attempts to connect the entrepreneurial process with entrepreneurial ecosystems (Spigel and Harrison 2018) by engaging in the nascent stages of ecosystem creation to suggest that initial opportunity beliefs may change considerably, that is, co-evolve over the course of developing confidence towards the opportunity as well as the ecosystem in general. The confidence to act on an opportunity lies at the end of a pathway of continuously developed and modified ideas (Davidsson 2015; Dimov 2007, 2010). Third, by approaching the SEE as something not-yet-realized but still in the making, i.e., a design artifact (Dimov 2016; Selden and Fletcher 2015), we provide a new theoretical foundation for understanding entrepreneurial ecosystems as a process of world-making.

\section{Literature review}

2.1 A process view on sustainable entrepreneurial ecosystems

The concept of entrepreneurial ecosystems has gained in popularity in the past decade, on the one hand due to rising attention paid to it by researchers (Audretsch and Link 2017; Spigel 2017; Spigel and Harrison 2018) and, on the other hand, because of increasing interest from public, private, and civil society actors (Autio et al.
2018; Simatupang et al. 2015). The basic notion is that everything in a system or ecosystem is interconnected and that the actions of any given actor directly or indirectly influence other actors in the system (Spigel 2017). Hence, no single actor can be considered in isolation and, instead, a systemic perspective is called for, as described in the original description of an entrepreneurial ecosystem by Cohen (2006):

[...] a diverse set of inter-dependent actors within a geographic region that influence the formation and eventual trajectory of the entire group of actors and potentially the economy as a whole [which] evolve through a set of interdependent components which interact to generate new venture creation over time. (Cohen 2006, pp. 2-3)

However, thus far, only few authors have explicitly employed the concept of a sustainable entrepreneurial ecosystem (SEE) (Theodoraki et al. 2018). Recently, Bischoff and Volkmann (2018) highlighted the necessity of initiating this conceptual development by merging the sustainable entrepreneurship literature with entrepreneurial ecosystems, for instance proposing that engagement in sustainable venturing likely leads to greater strength of the SEE. In his paper, Cohen (2006) presented the example of a sustainable valley in Victoria, Canada, where a cluster of innovative sustainable technologies was developed. Uddin et al. (2015) investigated the implementation of a SEE in the green IT sector, and Simatupang et al. (2015) examined the creation and development process of SEE to support innovation and new business creation. In this last case, SEE is understood as a long-term entrepreneurial ecosystem and is not directly related to sustainable entrepreneurship. A recent literature review (Bischoff and Volkmann 2018) highlights the importance of connecting sustainable entrepreneurship with its prominent process view (e.g., Belz and Binder 2017; Farny et al. 2018; Munoz and Cohen, 2018), which has been absent in the original definition as "an interconnected group of actors in a local geographic community committed to sustainable development through the support and facilitation of new sustainable ventures" (Cohen 2006, p. 3).

A process perspective of entrepreneurial ecosystems emphasizes on-going "development and flow of entrepreneurial resources such as human and financial capital, entrepreneurial know-how, market knowledge, and cultural attitudes" (Spigel and Harrison 2018, p. 152). 
The process literature has many types of explanation, including creativity (Dimov 2007) and self-reflexivity (Sarason et al. 2006), as well as conceptualizations of the entrepreneurial journey as an emergent process in which abstract ideas are converted into tangible ventures (Dimov 2007; Lichtenstein and Kurjanowicz 2010).

At the center of a process view on entrepreneurial ecosystems lies the presence and circulation of resources and how they evolve over time (Spigel and Harrison 2018). Spigel (2017) suggests that an ecosystem is composed of specific isolated attributes and the interactions between them, and that some attributes assume an important role in facilitating these interactions. One example of such an interaction could be the conscious development of entrepreneurial ecosystems where interdependent components interact to generate new venture creation over time (compare Dimov 2018; McMullen and Dimov 2013). Beyond this, eco-industrial parks (Cohen 2006) or university incubators (Theodoraki et al. 2018), where a local geographic community is developed through social capital, are similar conscious attempts to create an integrated closed-loop system between manufacturers, consumers, and other societal and economic actors (e.g., Lambert and Boons 2002). The sequences of entrepreneurial acts, formally termed projects or enterprises, are of particular interest here (McMullen and Dimov 2013).

\subsection{The evolving idiosyncratic view on entrepreneurial opportunities}

A further gap in the entrepreneurial ecosystem literature is to be found in the lack of an explicit connection to opportunity development, as an essential part of the entrepreneurial process, in explaining entrepreneurial ecosystem emergence (Spigel and Harrison 2018). For instance, Mason and Brown (2014, p. 82) emphasize the study of the dynamics between:

a set of interconnected entrepreneurial actors (both potential and existing), entrepreneurial organisations (e.g. firms, venture capitalists, business angels, banks), institutions (universities, public sector agencies, financial bodies) and entrepreneurial processes (e.g. the business birth rate, numbers of high growth firms, levels of 'blockbuster entrepreneurship', number of serial entrepreneurs, degree of sellout mentality within firms and levels of entrepreneurial ambition) which formally and informally coalesce to connect, mediate and govern the performance within the local entrepreneurial environment.

These authors suggest focusing on the development of opportunities, alongside the development of an entrepreneurial ecosystem through certain key process interactions which take place in a community consciously catalyzed to take advantage of local framework conditions and local/regional geographical environments.

The literature on opportunity identification consists of three main interpretations, each of which imply a different role for the entrepreneurial ecosystem (Davidsson 2015). For some (e.g., Autio et al. 2018), entrepreneurial opportunity is objective, discovered, and centered on the entrepreneur, and the way in which an individual processes information affects which opportunities are discovered. In this view, scholars define entrepreneurial opportunities as "situations in which new goods, services, raw materials, markets and organising methods can be introduced through the formation of new means, ends or ends-means relationships" (Eckhardt and Shane 2003, p. 336). Shane and Venkataraman (2000) state that discovering opportunities is contingent on the possession of prior information necessary to identify an opportunity and the cognitive ability to value it. The ecosystem may be interpreted as merely a structure in which opportunities objectively exist and can be discovered and pursued.

For others (e.g., Alvarez and Barney 2007), opportunity is rather more subjective, enacted, inclusive and social cognition-based and centered on the entrepreneur and his or her information network. The idea of an entrepreneurial ecosystem means that the social embeddedness of entrepreneurs should not be investigated in isolation but instead by considering their social context - which ultimately impacts upon entrepreneurial outcomes (Bischoff and Volkmann 2018). New opportunities are created by how information is shared, construed, and acted upon (Foss and Klein 2017). Here, ecosystems may be interpreted as supportive environments for opportunity creation (see Table 1).

The third view, labeled the "Evolving Idiosyncrasy View" by Davidsson (2015), and somewhat used by Dimov (2011) and Sarason et al. (2006), posits that the term opportunity is predominantly used to denote a subjective and unproven idea. This idea already exists early in the process, yet it can change considerably during its course and acquire increasing "objectification" over time 


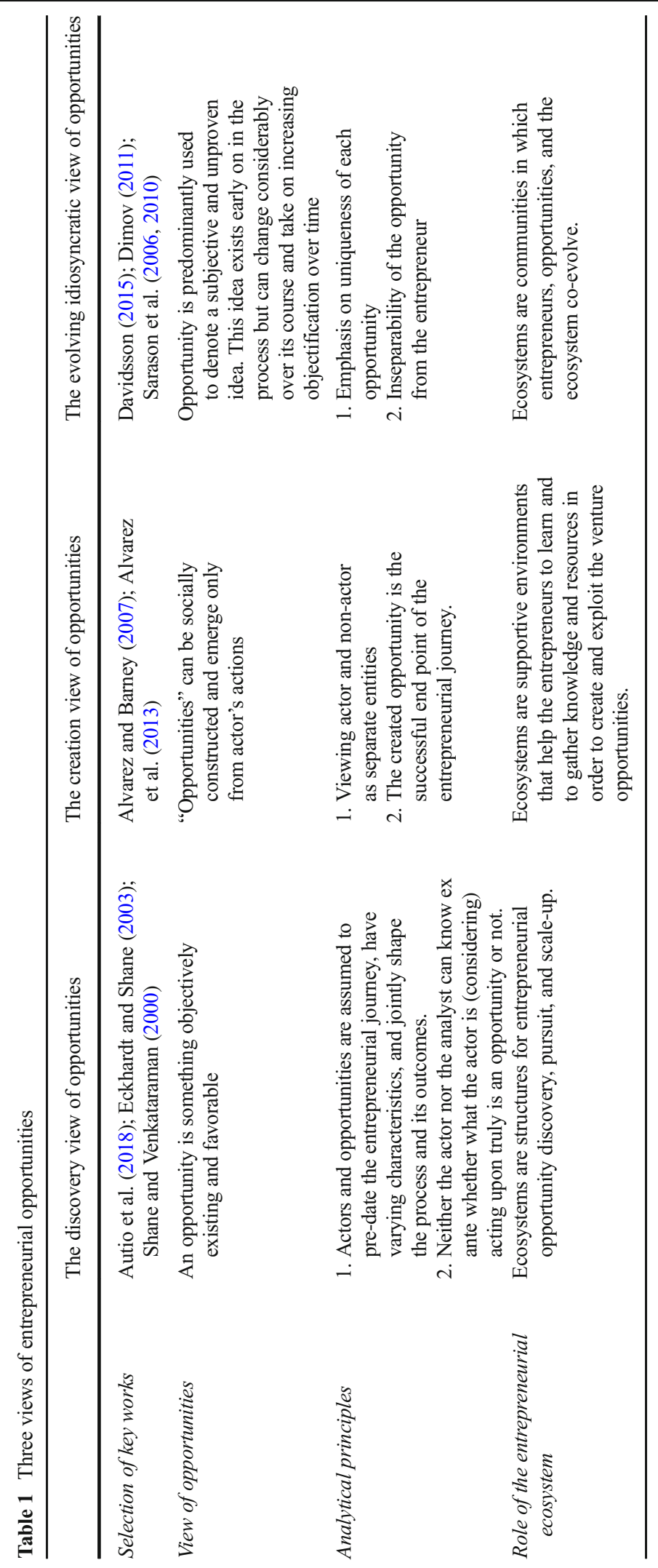


(Wood and McKinley 2010). Opportunity confidence (Davidsson 2015) refers to an actor's evaluation of what he or she perceives as an opportunity. The term opportunity confidence, originally introduced by Dimov (2010), is initially an individual-level, perceptual construct, although it can also emerge from social interaction (Dimov 2007). This is the stage at which a more formal entrepreneurial team may be formed as the idea shows continuing potential. Under the evolving idiosyncrasy view, the uniqueness of each opportunity is emphasized and the opportunity becomes inseparable from the entrepreneur. In this view, the ecosystem may be interpreted as the community structure that co-evolves together with the entrepreneur and the inseparable opportunities. With coevolution, we mean that early possibilities give rise to opportunity confidence and new venture development, and that this will affect the SEE, which in turn both affects the entrepreneurs themselves and their ability to identify, create, and exploit new opportunities.

\subsection{SEE as a learning system of co-evolving opportunities}

Integrating the process view on entrepreneurial ecosystems with an evolving idiosyncratic view of entrepreneurial opportunities, SEE becomes a "learning system." Following Dutta and Crossan (2005), we draw on insights from Crossan et al. (1999) 4I ("Intuiting, Interpreting, Integrating, and Institutionalizing") organizational learning framework to develop our argument on how new venture ideas are initially generated and then imbued with opportunity confidence. One of the 4I framework's strengths is that it adopts an orientation towards processes and a lens on the dynamic nature of opportunities which unfold as entrepreneurs engage with such processes. Dimov (2007) also highlighted the 4I process as a learning framework, where individuals engage in intuiting, which generates ideas with perceived potential; they then trigger a process of interpreting as they try to clarify those ideas both on their own as well as by engaging third parties to further refine and gain support for these ideas. Through these social interactions, a shared understanding of the opportunity idea begins to emerge, and thus, the overall learning process enters the integrating phase. Intuiting begins at an individual level and, in essence, denotes a growing awareness of a business idea that is seen as holding some perceived potential in meeting current or emerging customer needs. Individuals emerge from this process with an "inexplicable," pre-verbal sense of what is possible (Dimov 2007), whereas interpreting and integrating occur at a group level.

In the current debate, many scholars emphasize a general need to study the social networks and entrepreneurial processes beyond individual entrepreneurs and the organizations they create (Davidsson and Wiklund 2001). A small number of previous studies have already discussed opportunity creation as a constructive and interactive process (Fletcher 2006). As Shepherd (2015) suggests, this type of more social perspective could advance our understanding of the formation of opportunity beliefs. The development of the framework in this research approach studies the composition of the ecosystem and, specifically, the interaction of its various elements (Spigel 2017). It sees potential opportunity in terms of a process of social interaction and, therefore, as a social construction, rather than merely as an outcome of thinking that springs from the mind of the entrepreneur (Shepherd 2015), where the entrepreneurial actor is the community and where the uniqueness of the opportunity lies in how it is formulated by the community in its specific context. In this constructionist perspective, entrepreneurs construct their reality by interpreting and sharing information from themselves and their environment; by creating new knowledge and innovation; and by constructing opportunities. As Shepherd suggests, potential opportunities can be generated through abductive processes in the mind of an individual, yet the idea for that potential opportunity is then "triggered and developed by an individual experiencing the world" (Shepherd 2015, p. 3).

Both scholars and public policy makers are well advised to understand the conditions under which individuals acting in this SEE will work as a collective, with collective agency. Bratman (2014) recognizes that shared intentional activity requires both individual intention and adherence to certain social norms present in institutional arrangements and identifies the conditions necessary for the adoption of shared intentions. Bratman's (2014) approach to shared intentions allows for the study of groups doing things intentionally and in the interest of achieving group goals. Some individual intentions, particularly those pertaining to shared activities involving an element of interdependence, incorporate a greater degree of sociality. When actors' intended actions are interdependent, they develop shared intentions (Bratman 2014). In other words, shared intentionality supports or motivates collective 
agency. Importantly, such intentionality does not mean that actors' overarching intention to participate in the activity or their individual goals are the same. Shared intentions rely on interactions between actors in order for them to develop shared knowledge of each other's intentions to proceed, for these intentions to mesh, and for the actors to help each other achieve their goal.

\section{Research methodology}

\subsection{Research design}

To research how entrepreneurial opportunities coevolve within a sustainable entrepreneurial ecosystem, we follow principles of entrepreneurship as a design science: an intersubjective, path-dependent, and generative process in which opportunities are co-imagined design artifacts (Dimov 2011, 2016; Venkataraman et al. 2012). While the dominant conception in entrepreneurial studies is that of a natural phenomenon (that is, one to be described and explained retrospectively) (Dimov 2011), there is some momentum behind the idea of developing a perspective of entrepreneurship as a design activity (Dimov 2016). In this study, we build on this recent development and, in particular, embrace three aspects of entrepreneurship as a design process: (i) a social constructionist ontology, (ii) an intersubjective, generative epistemology, and (iii) a methodological understanding of process as a path-dependent sequence of events and activities.

First, the design science lens is distinct in that it studies systems that do not yet exist. Its orienting question is "Will it work?" rather than "Is it valid or true?" Design science has an interest in day-to-day practices that can hone judgment and develop rules of thumb that spur further research (Dimov 2016, 2017). With a social constructionist view, it is of interest to develop approaches and understandings of entrepreneurial processes, rather than to identify an ideal formula or assess success factors of individual organizations with an ambition to predict and prescribe a successful future (Fletcher 2006). In entrepreneurship, the design science approach can be viewed as a further development of the effectuation approach, recently labeled as a "science of the artificial" (Dimov 2016; Sarasvathy 2012), in which entrepreneurial narratives are treated as artifacts (Selden and Fletcher 2015; Venkataraman et al. 2012, 2013).
Second, design science calls for deliberate and reflective engagement, applying an intersubjective generative epistemology that is also found in action science. The practical fieldwork methods thus actively generate and analyze empirical data alongside the data collection process. From a social constructionist perspective (Fletcher 2006), all knowledge is constructed as the result of an interaction process that has been designed and deliberately initiated. Instead of seeing this as an unwanted deviation from the ideal of the neutral and unobtrusive scientist, we can see it as a contribution to both theory-building and practice (Gummesson 1988). Applying design principles, research processes are designed as mutual learning processes, an opportunity for practitioners and researchers to reflect and co-construct their identities (Lundin and Wirdenius 1990).

Thirdly, because design science views process as continuously emerging, becoming, and changing while actors develop understandings of their selves and their entrepreneurial reality (Simon 1996 [1969]), empirical enquiry intends to understand process as it unfolds. From a social constructionist perspective, entrepreneurial processes could be studied as open-ended series of events in which people jointly develop things (Dimov 2018; Fletcher 2006). A process perspective is important because it links the past to present and future events, thus enabling us to understand why things turn out in a certain way (Clarysse and Moray 2004; Sundin and Tillmar 2008). Such a process perspective further implies that we focus more on the means by which organization members go about constructing and understanding their experience, and less on the number or frequency of measureable occurrences. Studying SEE as a design science means that we broaden the level of analysis beyond individual accounts of entrepreneurial processes and move towards a coconstruction of useful and workable processes.

3.2 Empirical case: sustainable cellulose ecosystem project

The sustainable cellulose ecosystem project (SCEP) in question is a multidisciplinary research and innovation project focusing on finding new and innovative applications for cellulosic materials, and, in turn, creating a sustainable entrepreneurial ecosystem. Cellulose is the main component in plant cell walls and a main 
ingredient in paper production. A growing interest in non-oil-based materials has spurred new research avenues finding more sustainable material alternatives, and novel methods of using cellulose have become an active research topic due to its abundance in nature, as well as its biodegradability and chemical formability and tunability. The SCEP symbolizes all of Cohen's (2006) components of a SEE: (1) an interconnected group of actors, predominantly researchers in arts/design and various technological disciplines, in addition to local large and small companies and the main state organizations; (2) a local geographic community, centered on metropolitan Helsinki; (3) commitment to sustainable development, by developing bio-based, nanocellulose products; (4) the support and facilitation of new sustainable ventures based on a constantly increasing number of patents and startup funding. In the SCEP, the attempt is to transform the regional forest industry into a bioeconomy-helped by a change in emphasis at technical universities, which have started to actively search for new uses and bio-based materials to underpin a new knowledge-intensive and more sustainable ecosystem for wood-based industries (Haarla et al. 2018).

The development of the SEE was formalized in 2015 as part of the SCEP project involving over 100 people from 20 different organizations. The central goal of the project has been to actively and consciously combine new wood-based technology, material design, and business creation, partly through state innovation funding as an initial resource to kick-start the emergence of a new entrepreneurial ecosystem. The implementing organizations - research universities and public research laboratories - have an established and highly regarded knowledge base which employs significant numbers of scientists and engineers. Research organizations and universities often anchor entrepreneurial ecosystems in knowledge-intensive fields, and their technologytransfer offices are commonly identified as important engines of economic growth (Autio et al. 2018; Theodoraki et al. 2018).

\subsection{Data collection}

The data collection process contained a multi-stage longitudinal process examining the intentional creation of a SEE. We chose to study the SCEP because it provided us with a unique opportunity to obtain inside information on the early development of a SEE around a new and emerging technology. The project itself is overseen by a steering committee comprised of key stakeholders from all parts of Finnish society, including the ministries for work and labor and for the environment, regional development, and innovation agencies; the three major Finnish forestry companies; and medium and small start-ups in the field. In line with a design approach, the research team members were active participants in the project and partly directed the ecosystem development process in a series of ideation and venture-creation workshops. Data collection largely relied on participant interviews and reflections of participant experiences in the workshops.

Exploratory interviews were conducted (SeptemberNovember 2015) with six key experts to understand how members construct their experience and opportunity development efforts in order to broadly map the SEE. In this exploratory step, we gathered five expert opinions - representing perspectives from state-funded science, university science, design, and business - on the history, context, phases, roles, and the processes involved in the ecosystem. Following a semistructured interview guide, we asked the expert interviewees to describe how the emergent community (at the time, we used the term project) worked, what the key purpose was, what the history was, who was involved, what kept it together, which success factors took it forward, and which participants could represent the different organizations that were involved. Later, we returned to all five key informants twice to gather additional information and to discuss our interpretation of the information acquired from previous interviews.

Second, we conducted 25 semi-structured interviews (30 to 60 min each) with 20 participants of the ecosystem project between November 2015 and May 2016. They were chosen because they were key members of the extended project team, actively working day-to-day in creating the ecosystem and developing opportunities. We asked interviewees to describe how the community worked, what kept it together, and what the key success factors were. Third, we asked the participants in our final round of 13 interviews with 11 members (between late May 2016 and December 2016) to explain how ideas and opportunities are developed. These interviewees were chosen due to their role in nudging the ecosystem development and as active boundarycrossers and opportunity-developers. In addition, we attended over 30 project meetings, seminars, and reviewed the project documentation of more than 200 
pages (see electronic supplementary material for details of the data).

\subsection{Data co-construction and analysis}

A distinctive feature of design science is that data analysis follows a journey of world-making (Dimov 2016; Sarasvathy 2012). Therefore, the study's analysis process deviates from standard procedures of data collection and analysis, as the research team is actively involved in data co-construction. Nevertheless, we initiated the systematic data analysis only after all interventions were complete. It was in this way that we were able to follow standard procedures for inductive-abductive theory-building research in our process of abstracting theoretical ideas from the data by recursively going back and forth between data and emergent theoretical accounts (Farny et al. 2018; Gioia et al. 2013; Strauss and Corbin 1998).

\subsubsection{Step 1: exposing the building blocks of the sustainable entrepreneurial ecosystem}

Our analysis began with distilling the main building blocks of the ecosystem and its actors (Autio et al. 2018). This phase was largely informed by applying open coding (Strauss and Corbin 1998; Gioia et al. 2013) to our interview transcripts and interview notes, comprising more than 400 pages of data. Fundamentally, we coded all forms of enablers and actions that could be building blocks of a process for opportunity development. The 44 interviews led us to identify 202 different first-order codes. Adhering faithfully to informant terms (Strauss and Corbin 1998), open coding produced an initially large number of categories, requiring subsequent axial coding. Triangulating our interviewees' statements with one another, as well as with published project documents, helped to ensure a certain analytical rigor (Gioia et al. 2013; Leitch et al. 2010). This first analytical step resulted in exposing the main elements of the design artifact: the building blocks of the SEE.

\subsubsection{Step 2: identifying patterns of co-imagining entrepreneurial ideas}

In the second step, our focus was on understanding the relations between the building blocks as clusters of enablers that facilitate co-design. This axial coding process identified 40 such enablers, some of which were more fundamental than others, and some of which occurred earlier in the co-design process (the ideation phase) and some later (the development phase). We borrowed another basic assumption from Gioia that the people constructing their organizational realities are "knowledgeable agents" (Gioia et al. 2013, p. 17), in that people in organizations know what they are trying to do and can explain their thoughts, intentions, and actions. In the second step of the analysis, we therefore essentially let the data inductively guide our creation of second-order themes worth exploring in light of the existing literature (Gioia et al. 2013). The second analytical step resulted in developing a shared language to label SEE features and interrelations.

\subsubsection{Step 3: eliciting and theorizing the co-designed SEE processes}

The third step of the analysis finds the research team firmly in the theoretical realm, asking whether the emerging themes represent theoretical concepts that help us describe and explain the design artifact (the SEE) in relation to other contexts and in terms of the existing literature. We found that the work by Davidsson (2015) and Dimov (2007) reflected the second-order themes identified in the previous analytical step. From Davidsson's work (2015), we connected the concepts of new venture ideation and opportunity confidence, as they resonated with actors' experiences in describing the opportunity development phases.

Furthermore, Dimov (2007), following Crossan et al. (1999) and Dutta and Crossan (2005), highlighted the 4I process as a learning framework, where individuals engage in intuiting that generates ideas with perceived potential; they then trigger a process of interpreting. In Dimov's reference to 4I, interpreting is the "explaining and defending of fuzzy images of insights" (Dimov 2007, p. 723). In this process, potential entrepreneurs engage in explaining and defending the "fuzzy" images of their insights not only in their immediate social network but also with some potential partners, informal and formal investors, consultants, accountants, customers, suppliers, and employees. Through these social interactions, a shared understanding of the opportunity idea begins to emerge, and thus, the overall learning process enters the integrating phase. To cluster the enablers within the process, we borrowed from Dimov's (2007) $4 \mathrm{I}$ model, because in our interpretation, the social 
interaction, the "co-" element in collaboration, was a key differentiator for our process compared to earlier, more individualist interpretations of opportunity development. One key respondent remarked that "combining knowledge leads to leaps forward, and that breakthroughs come not from technology but from co-operation" (no. 17).

As a result, the three-stage analytical process led to the identification of five aggregate theoretical themes, which we saw as fundamental building blocks of SEE development: shared intention and emotional climate as meta-enablers, and three phases within a sequential process: co-intuiting, co-interpreting, and finally co-integrating. Once we had identified these aggregate theoretical themes, we became able to build a data structure (see Fig. 1), which is a key component of demonstrating rigor in qualitative research (Gioia et al. 2013).

\section{Findings: three opportunity co-evolution phases}

Our findings suggest that the opportunity evolution process within the SCEP has three main phase elements of co-intuiting, co-interpreting, and co-integrating, working to produce new venture ideas and opportunity confidence. Our analytical identification of elements of the opportunity co-construction process facilitates a deeper, more temporal understanding of SEE development. To understand this process, we applied the under-appreciated evolving idiosyncratic view and examined the gradual development of opportunity confidence in the SEE. By embracing a design science approach, we involved a range of stakeholders in the project to validate our thinking. We participated in formal and informal meetings with scientists, designers, and business representatives where we presented our findings and, through discussions, tested the generalizability and feasibility of the identified process. In this way, we were able to derive a useful model that represents the codesigned SEE artifact that project members had imagined, which helped us to structure ecosystem features and provided us with a useful communication tool to explicate the co-evolution of entrepreneurial opportunities. In the following, we illustrate our findings of this design process, first by presenting the three different phases before proceeding to integrate them into a practical framework.

\subsection{The first phase: co-intuiting}

Co-intuiting can be defined as initial joint activities that help develop vague ideas on technical, design, and financial possibilities. Our analysis revealed that the first phase essentially consists of co-ideating, "quick-anddirty" prototyping, and creating own insights. Co-ideating refers to jointly generating new ideas, sometimes by co-experimenting with novel materials. Overall, the first phase is characterized by idea divergence. Fresh ideas may originally come either from an individual working alone at speed in the lab or sometimes spring from formal workshops (e.g., using specialist facilitators and cottage-style retreats) by sketching out future alternative possibilities. In the SCEP, participants believed that truly novel ways of working with cellulose will come from understanding different ways of working - transdisciplinary working - and from boundary-crossing, in particular interlinking new ideas and approaches based on the diversity of the participants and the possibility of synergies.

Co-intuiting also requires actors to isolate themselves temporarily in order to create their own insights. As long as the SEE is not yet defined, participants sometimes have to follow their initial individual intuition, which in itself requires a strong prior knowledge level in their particular field of expertise. Some participants immersed themselves regularly in the academic and scientific literature in their field as a form of inspiration, and looked for an obvious opportunity derived from looking at the scientific literature. As such, there is a large degree of experimentation; for example, one of the senior design researchers would retire to her own workshop to work on individual enquiries into the material properties and experiment to find uniqueness that could become valuable grounds for opportunities later in the process: "Yeah I think it's in a way that a fresh idea ...to make something else than the traditional paper or things like that out of wood" (Interviewee no. 7, henceforth abbreviated "no. 7").

Co-ideation and individual experimentation are often followed by what the participants term quick-and-dirty prototyping. In the words of one designer: "The main thing is to go away...I can really start to play with the materials" (no. 7). Prototyping further consists in testing material properties and possible production methods, and using the materials to create relatively raw concept objects that display the material's qualities. In quickand-dirty prototyping, participants develop partly 


\section{First-Order Codes}

Second-Order Themes
Aggregate Theoretical Theme
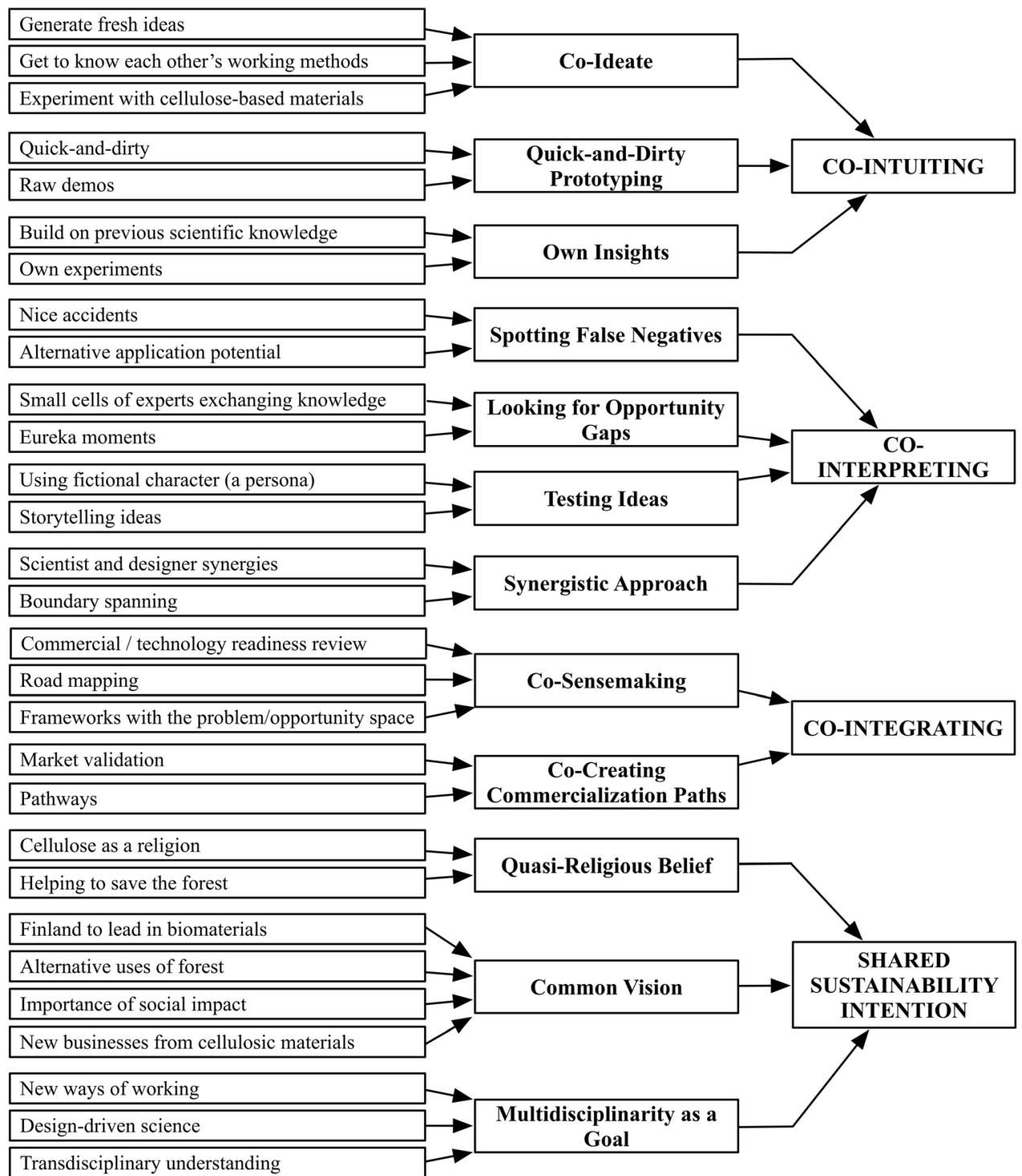

Transdisciplinary understanding

\begin{tabular}{l}
\hline Intrapreneurial aspirations \\
\hline Think business \\
\hline Curiosity \\
\hline Passion for science
\end{tabular}

Passion for Renewal

Passion for science

\begin{tabular}{|l|}
\hline Already close \\
\hline Openness \\
\hline Positively critical \\
\hline Train to trust \\
\hline Flat, no hierarchy \\
\hline Freedom in work \\
\hline Borderless, open \\
\hline
\end{tabular}

for
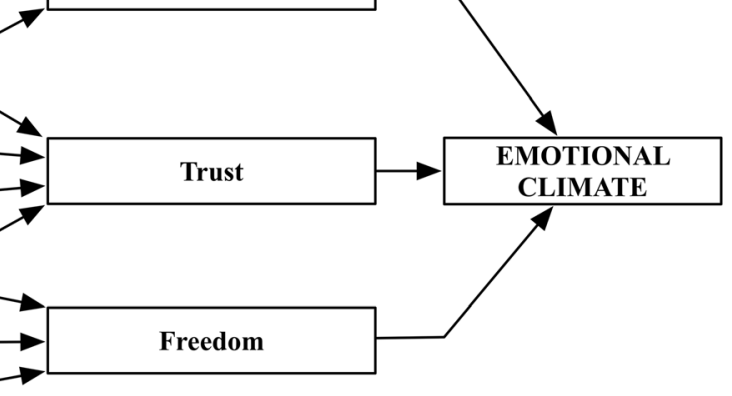

Fig. 1 Data structure 
imaginary and partly real combinations of product and service offerings, which are nominally given potential markets or users and routes to market. A prototype can then demonstrate raw objects or examples of new venture ideas with varying characteristics to participants to test their reactions.

This first phase of co-intuition elicits an earlystage iterative process which is characteristic of design thinking (Dorst 2011), where the participants favor experimentation over elaborate planning and use collegial, communal feedback to drive further iterations. Table 2 presents illustrative quotes for the three theoretical themes that comprise the first phase of the SEE opportunity development process.

\subsection{The second phase: co-interpreting}

In the co-interpretation phase, potential entrepreneurs engage in explaining and defending the fuzzy images and demonstration items of their insights. Cointerpreting can be defined as jointly making sense of potential ideas and identifying possibilities with a high likelihood for success. In the case of the SCEP, this consists of spotting false negatives, looking for opportunity gaps, testing ideas, and pursuing a synergistic approach (see Table 2).

Chesbrough (2004) introduced the concept of false negatives in product development, where an open innovation approach revealed alternative application potential in product development projects that had been considered to be of little or no value. Spotting false negatives describes a similar activity. As an example, scientists (no. 8, no. 12) had seen the results of an experiment with materials - in this case, a ruching effect (a gathering or pleating effect) from 3D-printing cellulose on fabric (as the cellulose dried) - as a negative characteristic until one of the designers saw the potential in ruching effects within fashion textiles. Several interviewees (no. 7 , no. 12, no. 17) noted this "nice accidents" effect.

In the SCEP, looking for opportunity gaps occurs within small cells of participants exchanging knowledge in pairs or groups of three. The wider nascent system of about 80 people splits into small cells of two or three individuals working across disciplines in a form of bisociation. Multidisciplinary work in these small cell-like groups offers numerous advantages. Such constellations deal better with complexity, foster creativity, and results have greater impact and cater to larger audiences. For co-development of opportunities, it has been a benefit to focus on the technical, functional, and perceptual characteristics of materials alongside each other. This integrated multidisciplinary approach to looking for opportunity gaps that focuses simultaneously on all three types of characteristics is desirable because materials need to respond to complex and interrelated design requirements. Eureka moments are created by having the different perspectives of small cells of different specialists working together under a common platform: "Maybe that gives us some benefit if it's working in a way that, but in a way that is something unique that may not be able to be done in all places" (no. 18).

A major activity in co-interpreting is the testing of ideas. This initially takes place in a series of workshops to test the quick-and-dirty concepts and simple objects (prototypes) that have already been created via co-intuiting. The aim in this phase is to further concretize fuzzy possibilities into product ideas which can be developed into product mock-ups or demonstration artifacts and subsequently can be pursued as serious opportunities. In the SCEP, Cellulife Workshops were organized by members of the design group as 1-day, intensive design-driven seminars for designers, scientists, and business specialists to explore and visualize future applications of cellulose. The workshops included a guided design activity geared towards the development of customer journey maps, that is, visual interpretations of a story from an individual's perspective of his or her relationship with the possible product over time. This is done by developing "personas" (Dorst 2011): main characters who illustrate the needs, goals, thoughts, feelings, opinions, expectations, and pain points of a user across a defined timeline. For example, one of the material designers (no. 7) had created small tubular structures from nanocellulose, which were extremely strong, lightweight, and biodegradable. One Cellulife Workshop resulted in a persona and subsequent storyboarding of such nanocellulose tubular structures which determined that they might be appreciated by hikers and outdoor enthusiasts who value sustainability. Such tubes could be used in hiking equipment to replace plastics and carbon fiber in tent poles, walking sticks, stool legs, kayak paddles, and so on. 
Table 2 Illustrative evidence of coded constructs

Aggregate theoretical Theme Illustrative data example with first-order code and interviewee ID
theme
theme

Co-intuiting

Co-ideate

"Quick-and-dirty"
prototyping

Own insights

Co-interpreting

Spotting false negatives

Looking for opportunity gaps

Testing of ideas

Synergistic approach

Co-sense making
"We have had a ...like a brainstorming session...there was a, I guess, one of these professional guys who explained about different techniques, coming up with ideas, and things like this. And we got a few key ideas ... let us say, was one like health and well-being, construction, and I think textiles" no. 15 (Generate fresh ideas)

"It's possible to work this so-called multi-discipline? Actually, there's many good examples of their benefits" no. 17 (Get to know each other's working methods)

"Yeah, at least from the technology point of viewing, it's definitely ... normally we generally do what's sort of quick-and-dirty trial ourselves in the lab to concept before bringing it forward" no. 15

"Because what we... have usually really boring demo ideas, that they are like no, we are not doing that! And then they suggest something else and we are like umh, sounds bad or that's not gonna work, but then we...further... and usually the outcome is like...wow!" no. 17 (Raw demos)

"I can take credit for inventing something, but I think the inspiration for it was that it's been lurking around I guess in the science community for maybe 10 years" no. 8 (Build on previous scientific knowledge)

"The main thing is to understand how it works, to find the uniqueness in the materials" no. 7 (Own experiments)

"We recognized that okay that happens.... So actually, this is what's a very nice examplewhy to combine these different organizations. Because these kinds of scientists working with materials, and they see something and then ... actually the result was that ... you can see that actually that is something that we need' no. 12 (Alternative application potential)

"So actually, this is very nice accident. So we have recognized, okay that when you print cellulose fabric, it very easily makes the 'ryppy' [wrinkling]. What is the...wrinkling...kind of. And actually, that was a problem. Then Pau [a designer] saw that actually this is something very difficult to do with textiles" no. 17 (Nice accidents)

"Combining knowledge leads to leaps forward, and those breakthroughs come not from technology but from co-operation"

So, you could say it's really important fact that ... you to work with arts? ... Well I would say that that was crucial" no. 8 (Small cells of experts exchanging knowledge)

"We all knew that when we have people coming from different organizations and cultures and different fields of science... after that, when people then start talking with the same voice, from the same things, then I believe that this eureka happens" no. 14 (Eureka moments)

"This is done by developing 'personas', main characters that illustrate the needs, goals, thoughts, feelings, opinions, expectations and pain points of a user across a defined timeline" no. 20 (Using fictional character - personas)

"Cellulife Workshop resulted in a persona and a resultant story-boarding of such nanocellulose tubular structures and determined that they might be appreciated by hikers and outdoor enthusiasts with strong eco-friendliness value systems" no. 13 (Storytelling ideas)

"Designers have curiosity...Designers are ideators and applicators... It has been crucial to work with artists" no. 8 (Scientist and designer synergies)

"I think at least with our work package, whenever we have the meeting after meeting, usually we are doing tour of the facilities that we might have... crossing the boundaries ... we started to rotate them a bit. ....... and you see the process inside these... So I guess this has helped" no. 15 (Boundary spanning)

"So even though you can do something in your kitchen...... What would be required in order to make a true business... even though it would be small but still sort of really solid case. ... what are the sort of steps that need to be taken here in order to really realize this kind of business" no. 4 (Frameworks with the problem/Opportunity space)

"But I think that inside the project the important thing ...is a way that you can really start doing something. More than just these very small pieces...Then I think that your work of putting these technologies into the same matrix, I think that that has been really important. That has been sort of shown in practice what we have in hand, I mean which level. So, I think that has been from a very practical point of view, an important thing" no. 4 (Commercial/Technology readiness review) 
Table 2 (continued)

Aggregate theoretical Theme theme
Illustrative data example with first-order code and interviewee ID
Co-creating commercialization paths

Shared sustainability intention

Common vision

Multidisciplinarity as a goal

Passion for renewal
"What would be required in order to make a true business even though it would be small but still sort of really solid case. So, this kind of... steps that need to be taken here...in order to really realize this kind of business... it (seems) that some model of working is really sort of great" no. 4 (Road mapping)

"The aim is to suggest pathways from idea to start-up that blend the ideation work, the prototyping or mock-up work, and then finally the necessary work on competitors, pricing and pitching preparation to gain the funding needed to continue" no. 4 (Pathways)

"I think it's quite good since ultimately these are the people of the companies that we are targeting at the end of the day. So, from one point of view, if these are potential customers, potential clients, it's only natural to hear what they thought and their opinions, and even what their suggestions or criticisms might be. And certainly, to engage industry and the greater public at the same time" no. 4 (Market validation)

"I think the cellulose is religion in this place... a kind of purity of this place" no. 22 (Cellulose as a religion)

"Yeah, and then I think somehow the interest is to save the forest, save the Finnish economy, save all that" no. 21 (Helping to save the forest)

"The big driver was to develop new added value uses for wood-based biomass in Finland because wood-based biomass is the biggest natural raw material source in Finland, or the only one, if you do not count the water" no. 22 (Finland to lead in biomaterials)

"The need for renewal or transformation of the industry...the vision was that...this is not just one of those cellulose modification projects, this is something more" no. 14 (Alternative uses of forest)

"Our project is an important thing for Finland ... yes, I think so. So, it's possible to do things differently" no. 17 (Importance of social impact)

"Yeah, I think it's in a way that a fresh idea to make something else than the traditional paper or things like that out of wood" no. 18 (New businesses from cellulosic materials)

"The vision was to create a new way of working in material research" no. 14 (New ways of working)

"A new way of working to involve design at the leading, or not as a leading instrument, it is a design-driven work. We started learning how to work in a design-driven project" no. 14 (Design-driven science)

"Multidisciplinarity is a goal in the project description, and multidisciplinary work is to be supported and strengthened as an important resource for the future of work in the country as a whole" no. 4 (Transdisciplinary understanding)

"Because I think that if you think about Ti, she's sort of all the time thinking about how this could be a business - and how she actually is to think.... together in business" no. 8 (Intrapreneurial aspirations)

"It's nice to know something and you have to know the fundamentals, but at the end of the day...I think ... [thought] should be given to how to get the benefit out of ...how to upscale" no. 8 (Think business)

"We are eager to understand new things ... I am curious ... we are open-minded about new things" no. 7 (Curiosity)

"I would like to say passion. Some people do have the passion for the science here" no. 12 (Passion for science)

Trust

"One other thing which I think is interesting, is that VTT and Aalto are extremely different cultures, organization cultures. The people - Well I would say that VTT and Aalto - Are not so different yeah... those are the people who used to work in Aalto... They are the same people... Absolutely, so they have the same sielu [soul] you might say" no. 17 (Already close)

"The key, I think, is trust and openness because the people who are coming from different disciplines do have very different views on research and how to do work together. So, I think that the trust and then openness are the things; they are the keys" no. 14 (Openness)

"I think it's important for the other person to say if he really does not think this is a good idea, even if you like the person you will be better off, or you will take more easily or in a better way if he says I do not think this is good. ...being 
Table 2 (continued)

\begin{tabular}{|c|c|c|}
\hline $\begin{array}{l}\text { Aggregate theoretical } \\
\text { theme }\end{array}$ & Theme & Illustrative data example with first-order code and interviewee ID \\
\hline & \multirow{5}{*}{ Freedom } & $\begin{array}{l}\text { open...but then being open to critique and trusting enough that the critique feels } \\
\text { positive somehow" no. } 12 \text { (Positively critical) }\end{array}$ \\
\hline & & $\begin{array}{l}\text { "What are the key success factors for this collaboration to work, among different } \\
\text { organizations, differently educated people, et cetera? I believe that it means } \\
\text { good coordination and people who want to get people to cooperate, and who } \\
\text { can also then, what is the right word, this idea of coaching people how to work } \\
\text { together, personally I think it's a great idea... to train the team that consisted } \\
\text { of people from different organizations to work together, in the beginning of the } \\
\text { project, it started this, and we had also other kinds of meetings than very official, } \\
\text { and also recreation day or something like that, and, team bonding" no. } 14 \\
\text { (Train to trust) }\end{array}$ \\
\hline & & $\begin{array}{l}\text { "And our team meetings, they are very 'epävirallisia' [informal]; there's - no } \\
\text { hierarchy. At least, very low hierarchy" no. } 18 \text { (Flat, no hierarchy) }\end{array}$ \\
\hline & & $\begin{array}{l}\text { "So, they are sharing and discussing, and it's nice to hear that people are free to } \\
\text { say that this did not work, we could not do this" no. } 18 \text { (Freedom in work) }\end{array}$ \\
\hline & & $\begin{array}{l}\text { "So, you need to be open all the time and think of... would this be useful somewhere?' } \\
\text { And what about ...it's the success factors ... And no borders actually" no. } 7 \\
\text { (Borderless, open) }\end{array}$ \\
\hline
\end{tabular}

In co-interpreting, a synergistic approach is used to derive synergies from collaboration between scientists and designers, and boundary spanning is encouraged. The diversity of participants in the nascent system has brought together different intellects from different organizations, with different lenses and a mix of various philosophies, thereby producing (unforeseen) synergies; and this has been a key enabler, according to many respondents. Several respondents (no. 7, no. 12, no. 14) remarked on the critical role played by designers in the SCEP when looking for opportunity gaps, due to the fact that they provide the interface between engineers and consumers, and that they can span the boundary lines between disciplines, as well those between scientists and the consumer. In this phase, multiple instances of "nice accidents" may occur, where transdisciplinary working can lead to eureka moments.

In short, co-interpreting is essential to progress in developing a SEE as it helps actors to explore possibilities formed in the co-intuiting phase and to concretize them through storyboarding and storytelling into more confident opportunities. These forms of internal collaboration are conducted around the preparation of mockups for later demonstrations. In the hiking example above, the decision was made to construct a hiking stool and kayak paddles as demonstration items. Cells of participants then explored possible competitor characteristics and retail price points in hiking and outdoor stores and presented possible mock-up ideas and intentions to project progress meetings, an iterative process built into the project way of working, to decide the prototypes on which to focus. The cells then produce the product prototype (or demo object), which can be used as a focal object (a proof of concept) when pitching opportunity ideas in the next phase.

\subsection{Third process phase: co-integrating}

Co-integrating can be defined as jointly evaluating the readiness of an idea and mapping out the future avenues for implementation. The co-integration phase resembles a convergence process where the evaluation - from negative to positive - of a possibility bestows opportunity confidence (Davidsson 2015; Dimov 2010). In essence, co-integrating refers to co-sensemaking and then cocreating commercialization paths (see Table 2).

Uniquely in the co-creation approach to SEE development, business specialists facilitate a general ecosystem and cellular-level co-sensemaking in arriving at convergence decisions in terms of which possibilities are to be promoted into opportunities that will lead towards partner-venturing, spin-off start-ups, or future funding options. Such sensemaking work - to co-enact the future - is a significant part of the third phase and helps with the general, collective, and prospective sensemaking process. Thus, sensemaking frameworks are presented to help with the mutual and individual sensemaking processes necessary for providing individuals in the community with a degree of clarity of direction in the medium and long term. In particular, a review 
of technological and commercial readiness was carried out to help convergence towards product ideas that will be taken forward either as spin-offs or as partnering ideas with corporate venturing arms. The project produced a traffic-light roadmap to help the project converge on key demonstration materials, processes, and opportunities. An influential interviewee (no. 4) pointed out that the peer technology-readiness and peer commercial readiness reviews had clarified the range of, and helped with convergence towards, the probable opportunities that were to be taken forward.

Alongside the technology-readiness review, a generic gap analysis was performed to roadmap the phases of work needed to be taken by the community in order to identify issues now faced by project opportunities in bringing them to market and to suggest how to bridge some of these gaps. The visuals that were produced aided the sensemaking process within the project and were used iteratively in the monthly review meetings to assess progress and to define the steps necessary for concretizing the opportunities. A key benefit of this approach for the SCEP is that it creates learning events around the communication associated with the development of the roadmap, particularly the need for aligning technology and commercial perspectives. The roadmaps serve as time-based and multilayered visual charts which provide a structured framework to reflect iteratively on the levels of confidence and possible pathways forward:

So even though you can do something in your kitchen. What would be required in order to make a true business even though it would be small but still sort of really solid case. ...what are the sort of steps that need to be taken here on in order to really realize this kind of business. (no. 4)

The business specialists within the nascent system play a further role in facilitating co-integration through $\mathrm{co}^{-}$ creating commercialization paths. Here, the aim is to suggest and then collaboratively develop pathways for the converged technologies and nascent business ideas towards technology transfer or start-up. The pathways blend the ideation work, the prototyping or mock-up work, and, finally, the necessary work on competitors, pricing, and pitching preparation in order to gain the resources (in terms of partnerships and funding) needed to continue. Co-creating these commercialization paths involves mapping opportunity pathways by building on the reviews for the levels of technological and commercial readiness with small teams or "cells" working on material technologies and mock-ups.

Alongside these potential commercialization pathways, market validation is provided by the voices of experienced industry and business professionals. This becomes a key integrating mechanism and convergence driver. The feedback is provided by experts in forestry, textile, and industrial composites. The social influences on the opportunity-development process pertain to the interpretation and integration inputs received by the potential entrepreneurs from the social audience with which they engage in discussing, selling, or defending their ideas. In the SCEP, perhaps the most valued feedback has come after, or during, large seminar displays and conferences from potential customers. Public disclosure pushes opportunity confidence in certain materials and contexts. In our empirical case, large domestic forestry companies are part of the external stakeholder community and have participated in workshops on several occasions annually to give feedback on possible value chains, partnerships for corporate venturing, and start-up support. These social contacts may provide the potential entrepreneur with access to various resources - in financial, technical, and marketing forms - that could potentially increase or shrink the scope of the initial idea.

As a result, this co-integrating phase drove the level of opportunity confidence to isolate those opportunities that could become technology-transfer opportunities as spin-offs from those that might provide benefits as stand-alone start-ups.

4.4 A process framework of sustainable entrepreneurial ecosystems

Based on our fieldwork and subsequent data analysis of the SCEP, we constructed a process model of how opportunities evolve through three interactionbased phases. Figure Fig. 2 visualizes the process framework as three phases, made possible by two fundamental enablers. A shared sustainability intention is the essential foundation, or cornerstone, for the development of the SEE and the process of developing opportunity confidence. It is the foundation also for a positive emotional climate to develop, which then iteratively further strengthens the shared intention. The shared 
S.E.E.

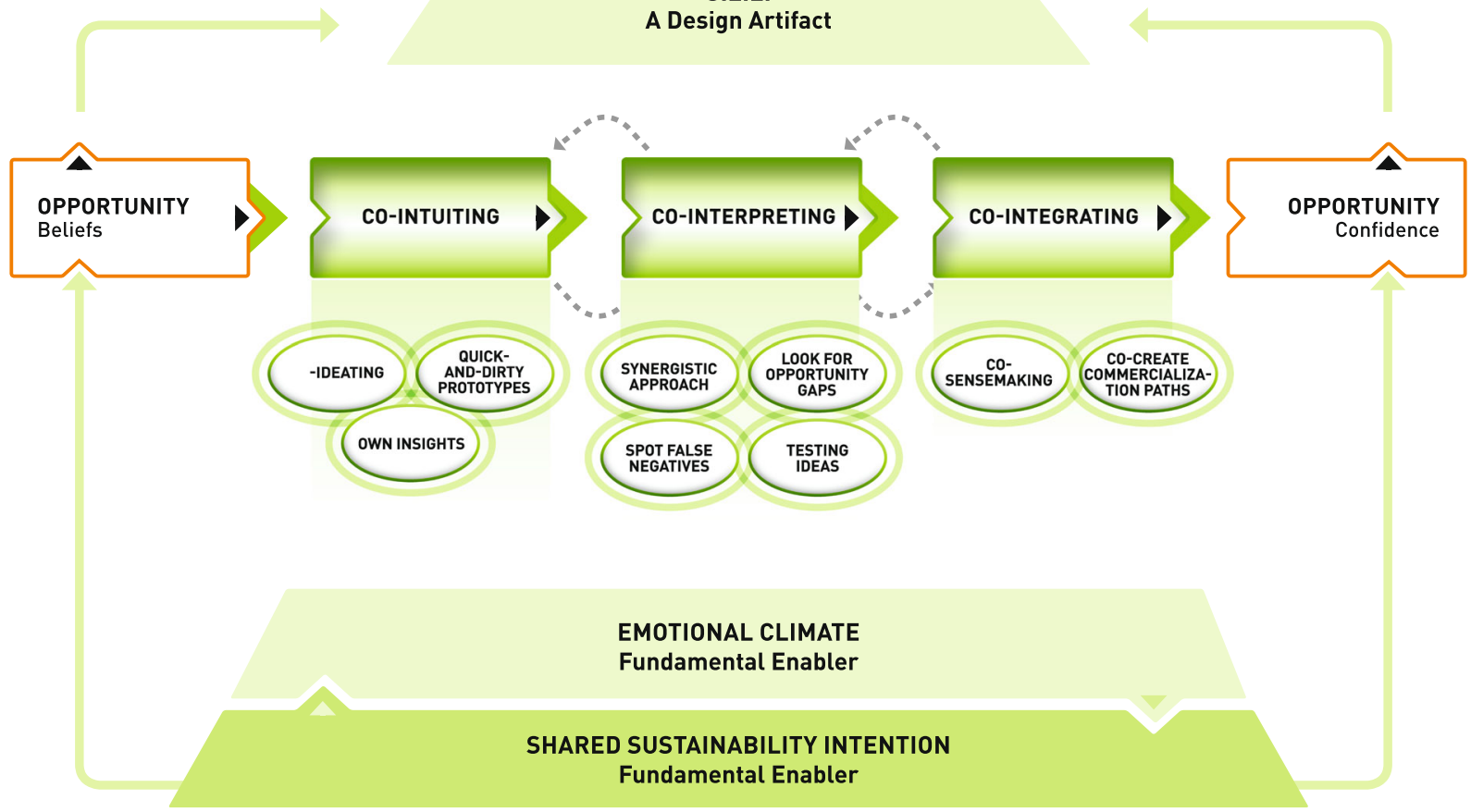

Fig. 2 Phases of opportunity co-evolution in a sustainable entrepreneurial ecosystem formation

sustainability intention and a conducive emotional climate function as cognitive and emotive meta-enablers. They develop linearly, over time, from an initial belief to result in the Sustainable Entrepreneurial Ecosystem through their enabling of all three co-construction phases in the opportunity-development process. The three phases are entrenched in complex and iterative collaborative social practice, and the opportunity coevolution process relies on these important metaenablers (a shared sustainable intention and a conducive emotional climate) to develop opportunity confidence.

\subsubsection{Shared sustainability intention}

A strong shared intention (Bratman 2014) is a powerful enabler for holding the nascent ecosystem together, and this shared intention in the SCEP is fundamentally about sustainability, that is, to save the Finnish forest (or help it prosper) as a natural and economic resource. The shared sustainability intention lies in the fact that individuals have a common expectation and commit to a joint activity (Bratman 2014). An emotional attachment to the forest can be observed in the location where the project takes place, and the forest has played a key role in that site's history (Haarla et al. 2018). Our data analysis shows that the shared sustainable intention has three elements: a quasi-religious belief, a common vision, and multidisciplinarity as a goal.

The first of these, a quasi-religious belief, centers on the role of the forest as a physical place and space, and as a source of wealth and health. Respondents describe a form of spirituality that they have with the forest, with timber and its components (e.g., cellulose) as something resembling a religion, and there is a common feeling that the SCEP is performing a spiritual quest in transforming the value of the forest. The SCEP is diverse in terms of characters and backgrounds, and it achieves coherence through a spiritual quest to find alternate, sustainable uses for the forest and alternative uses of wood materials - the large number of people from disparate backgrounds is held together by a "higher" shared purpose.

The SCEP emphasizes the importance of social impact as a primary objective that motivates project participants' engagement. In particular, the project aims to create new businesses dealing with cellulosic materials which can potentially have a large impact on Finnish society. A spontaneous and recurrent reference to social impact appears in interviews, and the message is clear 
that initiatives are fundamentally about socially beneficial innovation, and that profit and forms of financial value are not the immediate concern (e.g., no. 15, no. 17). The common vision lies in a systemic shift from the mass production of paper to a sustainable, value-added use of the forest, in order to fulfill a common desire to make better use of the forest, with the belief that it can be used for things other than the production of timber and paper. It is recognized that, through its expertise in cellulose material science and its natural access to wood resources, Finland can be a leader in the creation of a sustainable bioeconomy derived from the forest: "I would call it a shared purpose, and it's different from the goal, I see a higher purpose" (no. 22).

When participants' intended actions are interdependent, they develop shared intentions (Bratman 2014) and multidisciplinarity is a goal in itself. Individuals within the SCEP have personal intentions, but they are also bound together by a common belief that the perceived societal impact of the work in the nascent ecosystem is creating new opportunities from the forest through a "new way of working" which is multidisciplinary and interdisciplinary (see Table 2 for illustrative quotes).

\subsubsection{Emotional climate}

The emotional climate represents certain factors and practices that enable participants in the nascent ecosystem to combine the creative freedom to generate new venture ideas and generate opportunity confidence. One aspect of this working climate is a strong passion for renewal, to discover new aspects and new uses for cellulosic materials. There is a deep desire to grasp and challenge the newest material science to harness the possibilities of cellulose and to drive those possibilities towards business opportunities. These drives to investigate and discover possibilities are built on inherent curiosity and being open to new applications. A common passion is the willingness to direct the passion for science and discovery towards new business creation. The generic pathways to new business appear to come from either partnering with an already existing medium-to-large-scale business in the form of corporate venturing, or from a spin-off start-up style business coming directly from the SCEP. A common passion for spin-off thinking for partner-venturing and rapid up-scaling is clear.

There is a belief in the benefits of the fact that many of the participants in the SCEP already know each other and may have already worked together at some point, and that, despite differing scientific backgrounds, they are "already close," thus leading to the swift development of trust. This high level of trust means that they have the possibility to be "positively critical." To embed this enabler more strongly, the SCEP manager organized a particular form of team training so that participants could learn to appreciate each other's different work cultures, knowledge sets, and thought processes, and in particular so that scientists could learn to understand the "outcome model" of the designers and that the designers could understand the scientists' "measurement model."

A model for how the SCEP participants work together was evident in the high level of freedom within a formal structure which respondents considered to be important for allowing the work of new venture ideation and opportunity development to progress. Participants perceived benefits in having a form of systematic work alongside the freedom provided in a work system which had essentially no hierarchy. Openness was encouraged, and an emphasis was placed on speaking freely under the principle that there were no silly ideas. In addition, the team heard presentations on how designers and scientists work, and meeting venues were rotated so that some meetings were held in laboratories or studios in order to enable participants to physically cross borders and be more open about their work and how it is conducted. Furthermore, the monthly review and iteration meetings were rotated to give participants a feel for the working environment of the project's other organizations and to facilitate boundary-crossing. Interviewees commented that a key factor for success was that the cross-organizational and cross-departmental work seemed almost borderless, and that an inexperienced observer would view it as a single, organizational team at work. "And if you're sitting in the meeting, it's difficult to know which organization people are from" (no. 12).

\section{Discussion and theoretical implications}

Our chief interest in this study was to better understand opportunity co-evolution during the emergence of a nascent SEE. Recent research has found that the recognition and implementation of sustainable entrepreneurial opportunities is complex (Shepherd and Patzelt 2011) and requires both public and private support systems (Autio et al. 2018; Theodoraki et al. 2018). Therefore, we chose to investigate the entrepreneurial ecosystem - a concept which connects entrepreneurship 
policy and communities pursuing entrepreneurial opportunities (Spigel and Harrison 2018). Our analysis of a 3year journey of engaged scholarship within the SCEP suggests that the process of emergence for a sustainable entrepreneurial ecosystem can be understood as a series of entrepreneurial judgments (Foss and Klein 2017), or phases, that we label as co-intuiting, co-interpreting, and co-integrating. The adopted process view on entrepreneurial ecosystems (Spigel and Harrison 2018) and design science methodology in entrepreneurship (Dimov 2016,2017 ) allows us to study a sustainable entrepreneurial ecosystem that existed only as a design artifact, a dream of a more sustainable future in the making (Haarla et al. 2018), rather than in the sense of functioning firms or profit-driven activity.

In the following, we discuss how our findings contribute to the entrepreneurial ecosystems literature and generate implications for steering opportunity coevolution in sustainable entrepreneurial ecosystems. First, we clarify that a shared sustainability intent and supportive emotional climate are the buzz that keeps actors engaged in acting towards realizing the SEE. Second, we explain opportunity co-evolution in the SEE in order to intertwine the entrepreneurial process and entrepreneurial ecosystem literatures. We conclude our discussion with the general theoretical and methodological implications of treating the SEE process as a design science.

\subsection{Clarifying the buzz on sustainable entrepreneurial ecosystems}

To date, studies with an explicit focus on sustainability are rare in the entrepreneurial ecosystems literature (Bischoff and Volkmann 2018). In line with the overarching goal of this Special Issue, our study extends the entrepreneurial ecosystems literature (Autio et al. 2018; Spigel 2017; Spigel and Harrison 2018) by presenting a collaborative attempt between multiple actors to jumpstart a nascent sustainable ecosystem in a geographically delimited "community of inquiry" (Shepherd 2015). Our findings clarify that the initial process of deliberately creating an ecosystem is motivated and sustained by two meta-enablers: a shared sustainability intention and a supportive emotional climate. Bratman's (2014) work on shared intentional activities is informed in part by the behavior of complex collaborative systems (analogous to communities of inquiry). Shared intentional activity requires both individual intention and adherence to certain social norms present in institutional arrangements and identifies the conditions necessary for the adoption of shared intentions. When actors' intended actions are interdependent, they develop shared intentions (Bratman 2014). We show that through a shared sustainability intention and co-sensemaking in a favorable emotional climate, a SEE becomes more energized, specifically through the buzz generated before the actual businesses are established. This supports studies which suggest that valuable social ties intensify between ecosystem actors even when business ideas are eventually rejected (Piezunka and Dahlander 2018).

Furthermore, we suggest one possible conceptualization of the term sustainable in entrepreneurial ecosystems. In our view, sustainability in an ecosystem does not refer to an efficient, functional, and enduring (steady) state, but instead refers to the primacy of purpose-driven action, intentions, and interest among ecosystem actors. This view resembles the general turn in entrepreneurship research to view sustainability as purposefully contributing to societal well-being and environmental regeneration, while being financially sound (e.g., Binder and Belz, 2017; Muñoz and Cohen 2018; Shepherd 2015). To ascertain a prolonged, purposedriven collaboration between actors bound together neither by contracts nor necessity, a positive emotional atmosphere is beneficial (Farny et al. 2018). We find that the emotional climate enabler represents a foundational support that allows participants in the community to work within this strong, shared intention in order to combine their creative freedom and generate new venture ideas in a flat and open community that encourages cellular working. This also resonates with prior entrepreneurial ecosystem studies (Theodoraki et al. 2018) which have identified the contribution of social capital to the effective functioning of sustainable entrepreneurial ecosystems. Referred to as shared narratives, goals, and language (Theodoraki et al. 2018), these are in effect what we term "shared intentions." This suggests that certain elements of social capital among ecosystem actors may be crucial for the emergence of the SEE in the first place, thus inviting future research in this direction.

\subsection{Co-evolving opportunities in entrepreneurial ecosystems}

A recent critique of the emerging entrepreneurial ecosystem literature has pointed out that one shortcoming is the vagueness of the link to entrepreneurship, including 
entrepreneurial processes (Spigel and Harrison 2018). In essence, we contribute to this gap by emphasizing the role of entrepreneurial opportunities - a central feature of most entrepreneurship definitions (compare Dimov 2018) - in the formation of a SEE. To the best of our knowledge, our study is the first to apply an evolving idiosyncratic view of opportunities (Davidsson 2015; Dimov 2011; Sarason et al. 2006) in the ecosystem literature. We argue that this is a missed opportunity in itself, as the opportunity co-evolution emphasizes the circular, unpredictable nature of entrepreneurial intents, conceptually aligned with the design of an entrepreneurial ecosystem that is not yet realized but only in its formation. Thus, applying an evolving idiosyncratic view, we suggest that it is more useful to talk about opportunity beliefs of actors who gain confidence in the opportunity or various opportunities by trying to codevelop a SEE (Davidsson 2015). Thus, opportunity confidence lies at the end of a pathway of continuously developed and modified ideas (Davidsson 2015; Dimov 2007, 2010) in ecosystem formation.

Furthermore, the evolving idiosyncratic view of entrepreneurial opportunities provides a foundation for understanding action and agency in developing a process-view on ecosystems. We argue that opportunities emerge dynamically in social interaction between people involved in the development of the SEE. According to this approach, entrepreneurship emerges in interactions between individual actors and processes (Dimov 2016). While prior studies have identified the importance of both public and private support systems (such as, for example, incubators) in supporting the success of the sustainable ventures (e.g., Theodoraki et al. 2018), our findings add insights from within the SEE project. This contribution builds on the call by Brown and Mason (2017), who highlight the importance of studying ecosystems in terms of both structure and agency in order to appreciate the full complexity of the dynamics of entrepreneurial activity. This requires a deep understanding of the social environment (Belz and Binder 2017), but also includes a variety of relationships between various actors (Schaltegger and Wagner 2011).

Closely linked to this, we clarify the entrepreneurial process in entrepreneurial ecosystems (Spigel and Harrison 2018) by proposing that opportunity beliefs turn into opportunity confidence within the SCEP via three main process elements: co-intuiting, cointerpreting, and co-integrating (compare Fig. Fig. 2). In co-intuiting, joint activities help develop ideas on technical, design, and financial possibilities. In cointerpreting, ideas and objects created in the cointuiting phase are tested against possible customer and usage scenarios. In the co-integration phase, cosensemaking is emphasized in making the final convergence decisions as to which possibilities will be promoted into opportunities. Co-integration is hence a key phase for developing opportunity confidence among the potential entrepreneurs within the SCEP. This sensemaking takes place alongside the co-creation of commercialization pathways, including market exploration and validation work on price points, costing comparisons, and competitor positioning. Contacts with potential customers and resource providers, as well as intermediate external organizations, help actors adjust their assessment of the favorability of their new venture idea (cf. Dimov 2010) in a climate of trust and semipermanent feedback from inside and outside that leads to opportunity confidence.

Our objective has been to develop a viable framework for the micro-level study of how actors work as a collective that is able to imagine, investigate, and pursue new opportunities, when they are brought together, in the context of a project, specifically to build a sustainable entrepreneurial ecosystem. It is a key interest for sustainable entrepreneurship scholars to better understand the role of entrepreneurial action in "sustaining nature and ecosystems while providing economic and non-economic gains for investors, entrepreneurs and societies" (Shepherd and Patzelt 2011, p. 138). We develop a process model (Fig. Fig. 2) that serves as a framework for understanding how a SEE community imagines and pursues entrepreneurial opportunities and, hence, our framework provides several initial steps towards understanding the co-evolution of entrepreneurs and ecosystems as a series of entrepreneurial processes.

5.3 Towards a new theoretical foundation: approaching sustainable entrepreneurial ecosystem processes as design artifacts

At its most fundamental, our study is a timely response to the underdeveloped and under-theorized state of the ecosystem literature (Autio et al. 2018; Simatupang et al. 2015; Spigel 2017) and formulates a first attempt to develop a theoretical foundation for ecosystems as an artificial design artifact. Central to the premise for sciences of the artificial (Dimov 2016), we conceptualized the nascent ecosystem as something that was in the 
making and yet-to-be realized. In order to approach a phenomenon as artificial and in the making, we believe a design science view is most appropriate (compare Dimov 2018). In this vein, our paper is among the first to empirically implement a design science approach on entrepreneurship (a notable exception is Seldon and Fletcher, 2015).

Furthermore, the entrepreneurial process view then becomes one of world-making. This ontological view is inherent in our SEE framework on collaboratively designing a nascent sustainability-centered entrepreneurial ecosystem by co-intuiting, co-interpreting, and cointegrating ideas that have to be jointly imagined in the first place. As Dimov (2018, p. 20) explains:

We can relate to point $\mathrm{B}$ of an entrepreneurial process in two ways: (1) as something that has already happened and thus can be taken for granted; and (2) as something that is not yet realized and is thus in the making. These reflect, respectively, a retrospective and a prospective stance in how we describe the process. [...] in the second case, there is no future marker to signal a right path ahead. All we can see in a forwardlooking sense is a long chain of possible contingencies, forming an intimidating tree of possibilities.

Thus, approaching the ecosystem as something still to come into existence means taking a prospective stance. This provides a robust theoretical foundation to study entrepreneurial ecosystem formation with a process view (Spigel and Harrison 2018).

Methodologically, the ecosystem thereby becomes something to be imagined and created, which others have called a design artifact (e.g., Selden and Fletcher 2015). By taking a prospective stance through an engaged scholarship approach, our paper differs from the majority of previous studies on ecosystems, which are retrospective accounts of what happened or of what exists. We have been able to follow cohorts of prestart-up teams in a study that captures longitudinal data collected before and during a natural experiment, and this has provided rich, time-varying data on both new venture ideation and how opportunity confidence is gained. In this paper, we have shown how entrepreneurial actors took forward an initial opportunity belief and then, through common and mutual phases, turned this into entrepreneurial actions (Dimov 2011) and confident opportunities. Our findings may also be aligned with Foss and Klein (2017, p. 3), who suggest that "opportunity is a metaphor, a shorthand for the entrepreneur's beliefs, or judgments, about the uncertain future." Methodologically, we thus contribute by providing a research design well suited to investigate the process of how opportunity confidence forms in the SEE.

\subsection{Limitations}

From a social constructionist perspective, all empirical work is perceived as interactions between researchers and the people who are being studied. This means that all knowledge that is constructed is the result of an interaction process. While this is a limitation and an unwanted deviation from the ideal of the neutral and unobtrusive scientist, it can also be seen as a contribution to both theory-building and practice (Gummesson 1988), in which academic research is a mutual learning process for all of those involved (Lundin and Wirdenius 1990). Nevertheless, we would encourage further studies across different SEE to observe whether our conclusions are unique to the cultural context of the SEE we have studied.

Sustainable entrepreneurial ecosystems do not emerge quickly, and the question of whether 3 years is a sufficiently long period to follow the emergence of an ecosystem is legitimate. Our data collection covered the initial stage of SEE development, whereby we had to adjust the 4I learning framework. Our study does not look into the institutionalizing process - the fourth and final process in the 4I framework developed by Crossan and collaborators (Crossan et al. 1999) because, at the time the study ended, new enterprises were just being created and launched. While our intention was to study the SEE process only until the formation of opportunity confidence, rather than the entrepreneurial act of new entry as such, this leaves room for further studies to longitudinally investigate the functioning of the actual commercial community. At this stage, and also kindly pointed out by an anonymous reviewer, the goals of individual value creation and the collective goal of sustainable ecosystem may certainly collide at some point. Hence, further research could investigate what happens when SEE actors identify an opportunity that has the potential to increase value for the individual yet has a negative effect on the collective goals of the ecosystem. 


\section{Concluding remarks}

The purposeful development of sustainable entrepreneurial ecosystems figures on the agenda of policy makers as well as in the interests of scholars. For this reason, we identified a need to understand how such development occurs. Despite the emergent, uncertain, and effectual nature of the process, understanding how opportunities co-evolve in a SEE is a fundamental building block for designing effective policy measures as well as a guide for nascent entrepreneurs who wish the ecosystem to succeed. Entrepreneurs do not pursue opportunities they feel cannot be successful (Foss and Klein, 2018); hence, understanding how opportunity confidence evolves is a fundamental building block in the emergence of any given SEE.

The practical implication of our research builds on the identification of a set of design principles, described as themes in our "Findings: three opportunity coevolution phases" section (see Table 2), which are likely to be beneficial for any ecosystem development effort, regardless of context. Creativity leading to new opportunity beliefs often springs up along the boundaries of disciplines, and collaboration within the nascent SEE community has been a site for developing new practices, new services, and new products. Co-socialization processes are critical to innovation and, for entrepreneurs actually acting to start-up companies, they offer a promising, practical vehicle for their eventuation. Sarasvathy (2001) stated that "effectuation processes take a set of means as given and focuses on selecting between possible effects that can be created with that set of means" (p. 245). What we observe in the SCEP is that the nascent entrepreneurial ecosystem as a collective can also use effectual logic, thereby transforming possibilities in new material science into valuable new opportunities through interaction with others in a form of "coeffectuation."

Methodologically, we followed the principles of studying entrepreneurship as a design science - an intersubjective, path-dependent, and generative processin which opportunities are co-imagined design artifacts (Selden and Fletcher 2015; Venkataraman et al. 2012). While the dominant conception in entrepreneurial studies is that of a natural phenomenon (i.e., one to be described and explained retrospectively) (Dimov 2011), the momentum towards developing a perspective of entrepreneurship as a design activity has grown (Dimov 2016), just as has the need for frameworks that would seek to explain the means and principles of the entrepreneurial processes within a nascent SEE. To our knowledge, this study is the first to examine the joint design efforts of a new entrepreneurial ecosystem as an active participant in the process, and we hope to have been able to provide, if not a contribution in the strictest sense, at minimum a degree of methodological inspiration for a more engaged approach to be used by scholars studying ecosystems and entrepreneurship in general.

Acknowledgments We would like to thank the SI Editors and two anonymous reviewers for their support and developmental comments. We would also like to thank participants of the FGF Sustainable Entrepreneurship Working Group for valuable feedback on an earlier version of this paper.

Funding information Open access funding provided by LUT University. This study is part of the research project DWoC 2.0, funded by the Finnish Funding Agency for Technology and Innovation (Tekes), and also supported by "Package Heroes" Academy of Finland/Strategic Research Council (grant no: 320217).

Open Access This article is distributed under the terms of the Creative Commons Attribution 4.0 International License (http:// creativecommons.org/licenses/by/4.0/), which permits unrestricted use, distribution, and reproduction in any medium, provided you give appropriate credit to the original author(s) and the source, provide a link to the Creative Commons license, and indicate if changes were made.

\section{References}

Alvarez, S. A., \& Barney, J. B. (2007). Discovery and creation: alternative theories of entrepreneurial creation. Strategic Entrepreneurship Journal, 1(1), 11-26.

Alvarez, S. A., Barney, J. B., \& Anderson, P. (2013). Forming and exploiting opportunities: The implications of discovery and creation processes for entrepreneurial and organizational research. Organization Science, 24(1), 301-317.

Audretsch, D. B., \& Belitski, M. (2017). Entrepreneurial ecosystems in cities: establishing the framework conditions. The Journal of Technology Transfer, 42(5), 1030-1051.

Audretsch, D. B., \& Link, A. N. (2017). Embracing an entrepreneurial ecosystem: an analysis of the governance of research joint ventures. Small Business Economics, 1-8.

Autio, E., Nambisan, S., Thomas, L. D., \& Wright, M. (2018). Digital affordances, spatial affordances, and the genesis of entrepreneurial ecosystems. Strategic Entrepreneurship Journal, 12(1), 72-95.

Belz, F. M., \& Binder, J. K. (2017). Sustainable entrepreneurship: a convergent process model. Business Strategy and the Environment, 26(1), 1-17.

Bischoff, K., \& Volkmann, C. K. (2018). Stakeholder support for sustainable entrepreneurship-a framework of sustainable 
entrepreneurial ecosystems. International Journal of Entrepreneurial Venturing, 10(2), 172-201.

Bratman, M. E. (2014). Shared agency: a planning theory of acting together. Oxford University Press.

Brown, R., \& Mason, C. (2017). Looking inside the spiky bits: a critical review and conceptualisation of entrepreneurial ecosystems. Small Business Economics, 49(1), 11-30.

Chesbrough, H. (2004). Managing open innovation. ResearchTechnology Management, 47(1), 23-26.

Clarysse, B., \& Moray, N. (2004). A process study of entrepreneurial team formation: the case of a research-based spin-off. Journal of Business Venturing, 19(1), 55-79.

Cohen, B. (2006). Sustainable valley entrepreneurial ecosystems. Business Strategy and the Environment, 15(1), 1-14.

Crossan, M. M., Lane, H. W., \& White, R. E. (1999). An organizational learning framework: from intuition to institution. Academy of Management Review, 24(3), 522-537.

Dattée, B., Alexy, O., \& Autio, E. (2018). Maneuvering in poor visibility: how firms play the ecosystem game when uncertainty is high. Academy of Management Journal, 61(2), 466498.

Davidsson, P. (2015). Entrepreneurial opportunities and the entrepreneurship nexus: a re-conceptualization. Journal of Business Venturing, 30(5), 674-695.

Davidsson, P., \& Wiklund, J. (2001). Levels of analysis in entrepreneurship research: current practice and suggestions for the future. In Entrepreneurship (pp. 245-265). Berlin, Heidelberg: Springer.

Dimov, D. (2007). Beyond the single-person, single-insight attribution in understanding entrepreneurial opportunities. Entrepreneurship Theory and Practice, 31(5), 713-731.

Dimov, D. (2010). Nascent entrepreneurs and venture emergence: opportunity confidence, human capital, and early planning. Journal of Management Studies, 47(6), 1123-1153.

Dimov, D. (2011). Grappling with the unbearable elusiveness of entrepreneurial opportunities. Entrepreneurship Theory and Practice, 35(1), 57-81.

Dimov, D. (2016). Toward a design science of entrepreneurship. In Models of Start-up Thinking and Action: Theoretical, Empirical and Pedagogical Approaches (pp. 1-31). Bingley: Emerald Group Publishing Limited.

Dimov, D. (2017). The Reflective Entrepreneur. Taylor \& Francis.

Dimov, D. (2018). Entrepreneurial process: mapping a multiplicity of conversations. In W. Gartner \& B. Teague (Eds.), Research handbook of entrepreneurial behavior, practice, and process. Edward Elgar.

Dorst, K. (2011). The core of 'design thinking' and its application. Design Studies, 32(6), 521-532.

Dutta, D. K., \& Crossan, M. M. (2005). The nature of entrepreneurial opportunities: understanding the process using the $4 \mathrm{I}$ organizational learning framework. Entrepreneurship Theory and Practice, 29(4), 425-449.

Eckhardt, J. T., \& Shane, S. A. (2003). Opportunities and entrepreneurship. Journal of Management, 29(3), 333-349.

Farny, S., Kibler, E., Hai, S., \& Landoni, P. (2018). Volunteer retention in prosocial venturing: the role of emotional connectivity. Entrepreneurship Theory and Practice. https://oi. org/10.1177/1042258718769055.

Fletcher, D. E. (2006). Entrepreneurial processes and the social construction of opportunity. Entrepreneurship and Regional Development, 18(5), 421-440.
Foss, N. J., \& Klein, P. G. (2017). Entrepreneurial discovery or creation? In search of the middle ground. Academy of Management Review, 42(4), 733-736.

Gioia, D. A., Corley, K. G., \& Hamilton, A. L. (2013). Seeking qualitative rigor in inductive research: notes on the Gioia methodology. Organizational Research Methods, 16(1), 15-31.

Gummesson, E. (1988). Qualitative methods in management research: case study research, participant observation. Entrepreneurship Theory and Practice. https://doi. org/10.1177/1042258718769055.

Haarla, A., Hakala, H., \& O'Shea, G. (2018). Re-imagining the forest: entrepreneurial ecosystem development for Finnish cellulosic materials. In Entrepreneurial, innovative and sustainable ecosystems (pp. 191-214). Cham: Springer.

Lambert, A. J. D., \& Boons, F. A. (2002). Eco-industrial parks: stimulating sustainable development in mixed industrial parks. Technovation, 22(8), 471-484.

Leitch, C. M., Hill, F. M., \& Harrison, R. T. (2010). The philosophy and practice of interpretivist research in entrepreneurship: quality, validation, and trust. Organizational Research Methods, 13(1), 67-84.

Lichtenstein, B., \& Kurjanowicz, B. (2010). Tangibility, momentum, and the emergence of the republic of tea. ENTER Journal, 1(1), 125-148.

Lundin, R. A., \& Wirdenius, H. (1990). Interactive research. Scandinavian Journal of Management, 6(2), 125-142.

Mason, C., \& Brown, R. (2014). Entrepreneurial ecosystems and growth oriented entrepreneurship. Final Report to OECD, Paris, 30(1), 77-102.

McMullen, J. S., \& Dimov, D. (2013). Time and the entrepreneurial journey: the problems and promise of studying entrepreneurship as a process. Journal of Management Studies, 50(8), 1481-1512.

Muñoz, P., \& Cohen, B. (2018). Sustainable entrepreneurship research: taking stock and looking ahead. Business Strategy and the Environment, 27(3), 300-322.

Piezunka, H., \& Dahlander, L. (2018). Idea rejected, tie formed: organizations' feedback on crowdsourced ideas Academy of Management Journal. https://doi.org/10.5465 /amj.2016.0703.

Rockström, J., Steffen, W., Noone, K., Persson, Å., Chapin, F. S., III, Lambin, E. F., et al. (2009). A safe operating space for humanity. Nature, 461(7263), 472.

Sarason, Y., Dean, T., \& Dillard, J. F. (2006). Entrepreneurship as the nexus of individual and opportunity: a structuration view. Journal of Business Venturing, 21(3), 286-305.

Sarason, Y., Dillard, J. F., \& Dean, T. (2010). How can we know the dancer from the dance?: Reply to "Entrepreneurship as the structuration of individual and opportunity: A response using a critical realist perspective".(Mole and Mole, 2008). Journal of Business Venturing, 25(2), 238-243.

Sarasvathy, S. D. (2001). Causation and effectuation: toward a theoretical shift from economic inevitability to entrepreneurial contingency. Academy of Management Review, 26(2), 243-263.

Sarasvathy, S. (2012). Worldmaking. In Entrepreneurial Action (pp. 1-24). Bingley: Emerald Group Publishing Limited.

Schaltegger, S., \& Wagner, M. (2011). Sustainable entrepreneurship and sustainability innovation: categories and 
interactions. Business Strategy and the Environment, 20(4), 222-237.

Selden, P. D., \& Fletcher, D. E. (2015). The entrepreneurial journey as an emergent hierarchical system of artifactcreating processes. Journal of Business Venturing, 30(4), 603-615.

Shane, S., \& Venkataraman, S. (2000). The promise of entrepreneurship as a field of research. Academy of Management Review, 25(1), 217-226.

Shepherd, D. A. (2015). Party on! A call for entrepreneurship research that is more interactive, activity based, cognitively hot, compassionate, and prosocial. Journal of Business Venturing, 30(4), 489-507.

Shepherd, D. A., \& Patzelt, H. (2011). The new field of sustainable entrepreneurship: studying entrepreneurial action linking "what is to be sustained" with "what is to be developed". Entrepreneurship Theory and Practice, 35(1), 137-163.

Simatupang, T. M., Schwab, A., \& Lantu, D. (2015). Introduction: building sustainable entrepreneurship ecosystems. International Journal of Entrepreneurship and Small Business, 26(4), 389-398.

Simon, H. (1996 [1969]). The sciences of the artificial (3rd Eds). Cambridge: MIT Press.

Spigel, B. (2017). The relational organization of entrepreneurial ecosystems. Entrepreneurship Theory and Practice, 41(1), 49-72.

Spigel, B., \& Harrison, R. (2018). Toward a process theory of entrepreneurial ecosystems. Strategic Entrepreneurship Journal, 12(1), 151-168.

Strauss, A., \& Corbin, J. (1998). Basics of qualitative research techniques. Sage Publications.
Sundin, E., \& Tillmar, M. (2008). A nurse and a civil servant changing institutions: entrepreneurial processes in different public sector organizations. Scandinavian Journal of Management, 24(2), 113-124.

Theodoraki, C., Messeghem, K., \& Rice, M. P. (2018). A social capital approach to the development of sustainable entrepreneurial ecosystems: an explorative study. Small Business Economics, 51(1), 153-170.

Uddin, M., Hindu, R. C., Alsaqour, R., Shah, A., Abubakar, A., \& Saba, T. (2015). Knowledge management framework using green IT to implement sustainable entrepreneur ecosystem. Applied Mathematics \& Information Sciences, 9(5), 2703.

Venkataraman, S. (1997). The distinctive domain of entrepreneurship research. Advances in Entrepreneurship, Firm Emergence and Growth, 3(1), 119-138.

Venkataraman, S., Sarasvathy, S. D., Dew, N., \& Forster, W. R. (2012). Reflections on the 2010 AMR decade award: Whither the promise? Moving forward with entrepreneurship as a science of the artificial. Academy of Management Review, 37(1), 21-33.

Venkataraman, S., Sarasvathy, S. D., Dew, N., \& Forster, W. R. (2013). Of narratives and artifacts. Academy of Management Review, 38(1), 163-166.

Wood, M. S., \& McKinley, W. (2010). The production of entrepreneurial opportunity: a constructivist perspective. Strategic Entrepreneurship Journal, 4(1), 66-84.

Publisher's note Springer Nature remains neutral with regard to jurisdictional claims in published maps and institutional affiliations. 